\section{Esquizofrenia: adesão ao tratamento}

Itiro Shirakawa, editor. Cecília Attux, Fernando Sargo Lacaz, Stella Maria TC Malta, co-editores. Lemos Casa Editorial; 2007.

A falta de adesão ao tratamento ocorre em $50 \%$ dos casos de esquizofrenia e está diretamente associada a desfechos graves como o aumento do risco de suicídio, do uso de drogas ilícitas, internações, recaídas etc. A adesão ao tratamento é anterior a todo investimento humano, financeiro, científico no desenvolvimento de medicamentos mais eficazes. É condição sine qua non para os bons resultados do tratamento. No entanto, ela continua superestimada pelos médicos. ${ }^{1}$ Não garantimos ainda essa condição preliminar do tratamento da esquizofrenia e nem a dimensionamos adequadamente, o que torna o tema relevante e atual.

Apenas um terço dos pacientes são completamente aderentes. Outro terço é parcialmente aderente, quer dizer: falham de tempos em tempos em tomar a medicação ou reduzem as doses. A parcela final não segue as orientações de modo geral. ${ }^{2}$

O livro Esquizofrenia: adesão ao tratamento foi elaborado por um grupo de pesquisadores da Universidade Federal de São Paulo (Unifesp) que, a partir da visão da literatura e da experiência profissional do grupo, sintetizaram os fatores que favorecem a aderência ou que a prejudicam, bem como os recursos disponíveis para a superação desse limite intransponível para uma parcela expressiva dos casos.

A abordagem dos autores não só abarcou os aspectos medicamentosos da aderência (assunto um tanto desgastado), mas também, e quase principalmente, os aspectos não-farmacológicos do tratamento, abordagem que os tem distinguido entre aqueles que se dedicam ao estudo e tratamento da esquizofrenia.

Os primeiros quatro capítulos abordam os aspectos médicos da aderência, fazendo uma revisão dos principais fatores de risco para não aderência e indicando condutas específicas para o manejo de efeitos colaterais neurológicos imediatos e tardios, cognitivos, endocrinológicos, e outros. Há ainda um capítulo dedicado às disfunções sexuais secundárias ao uso de antipsicóticos.

A frase "o paciente não é o único responsável pela sua adesão ao tratamento" sinaliza a visão dos autores sobre o assunto: a aderência ao tratamento é uma questão complexa e multifatorial, e inclui elementos dinâmicos individuais e familiares, cognitivos, relacionais entre o médico e o paciente, culturais (estigma) etc. Portanto, a adequação da medicação em relação aos efeitos colaterais e eficácia é condição necessária, mas não suficiente para solução do problema.

Os autores dão uma visão geral dos diversos tipos de intervenções psicossociais, começando pela psicoeducação, que é uma das poucas intervenções que têm evidência comprovada de eficácia não só quanto à adesão. ${ }^{2}$ No entanto, no Brasil, ou mesmo Europa e EUA, é uma técnica pouco vista como cuidado de rotina.

O capítulo 5 aborda as estratégias psicológicas usadas no manejo da adesão e divide sua ênfase em cognitiva, de aumento do insight e intervenções psicoterapêuticas. Apesar das controvérsias em torno da eficácia das intervenções psicossociais quanto à adesão, observamos em nossa rotina que as mesmas, bem como os grupos de auto-ajuda, favorecem a adesão.

Há também um relato abrangente das técnicas operativas que, segundo a autora e a experiência do grupo, permitem uma integração dos focos das intervenções psicossociais.
$\mathrm{Na}$ revisão sobre as psicoterapias, os autores relatam uma tendência de afastamento do trabalho sobre o insight e maior valorização da psicoeducação, pois a eficácia dessas primeiras são controversas, o mesmo ocorrendo com a terapia ocupacional.

As técnicas de terapia cognitivo-comportamental visam explorar sintomas psicóticos e as vivências dos mesmos tendo apenas um efeito indireto sobre a adesão ao tratamento.

0 volume ainda oferece àqueles que queiram se aprofundar uma boa coletânea de referências bibliográficas sobre os temas abordados, bem como relatos de casos que ilustram situações específicas que envolvem aspectos da aderência a tratamento vistos na clínica psiquiátrica.

Belquiz Schifnagel Avrichir Projeto Esquizofrenia (Projesq), Instituto de Psiquiatria, Hospital das Clínicas, Faculdade de Medicina, Universidade de São Paulo (USP), São Paulo (SP), Brasil

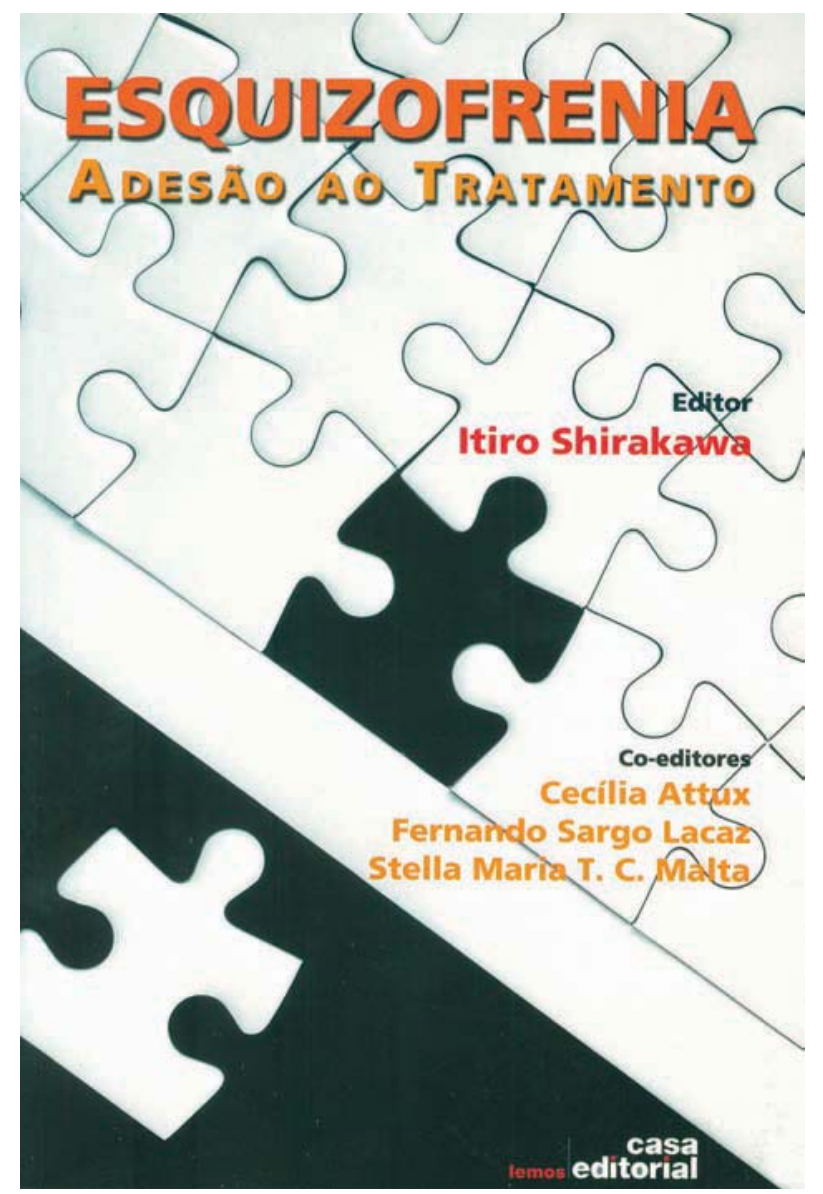

Referências

1. Hummer MO, Fleischhaker WW. Acta Psychiatr Scand. 2000;102(Suppl. 407):83-6.

2. Magliano L, Fiorillo A, Malangone C, De Rosa C, Maj M. Patient functioning and family burden in a controlled, real-world trial of family psychoeducation for schizophrenia. Psychiatr Serv. 2006;57(12):1784-91. 